\title{
Alpha lipoic acid bioequivalence study redesigned: a candidate for highly variable drugs
}

\author{
Burcu Bulut ${ }^{1}$ (D), Nagehan Sarraçoğlu¹ (D), Onur Pınarbașlı1 (i) \\ ${ }^{1}$ Ilko Pharmaceuticals, Research and Development Center, Ankara, Turkey
}

ORCID IDs of the authors: B.B. 0000-0002-9726-8577; N.S. 0000-0002-1222-7339; O.P. 0000-0001-7091-683X

Cite this article as: Bulut, B., Sarracoglu, N., \& Pinarbasli, O. (2021). Alpha lipoic acid bioequivalence study redesigned: A candidate for highly variable drugs. İstanbul Journal of Pharmacy, 51 (1), 8-15.

\begin{abstract}
Background and Aims: Alpha lipoic acid 600 mg HR film tablet showed high intra-subject variabilities in bioequivalence studies. In this regard, this study aims to determine whether Alpha lipoic acid $600 \mathrm{mg} \mathrm{HR}$ film coated tablet is a highly variable drug. Methods: First, a randomized, open-label, balanced, two-treatment, two-period, two-sequence, single-dose, two-way crossover oral bioequivalence study comparing the test product (Alpha lipoic acid HR film tablet - ILKO Pharmaceuticals, Turkey) with the reference product (Thioctacid ${ }^{\circledR}$ - Meda Pharma, Germany) was conducted in normal, healthy, adult human subjects under fasting conditions (Study 1). Secondly, a randomized, open-label, balanced, two-treatment, four-period, two-sequence, single-dose, fully replicate crossover oral bioequivalence study was conducted in normal, healthy, adult human subjects under fasting conditions (Study 2).

Results: Study 1 failed. It had a $90 \%$ confidence interval for $\mathrm{LnC}_{\max }(\mathrm{ng} / \mathrm{mL})$ value between $79.69 \%-138.98 \%$ with a high intra-subject coefficient of variability (ISCV=57.5\%). In study 2 a $90 \%$ confidence interval for $\mathrm{LnC}_{\max }(\mathrm{ng} / \mathrm{mL}) \mathrm{was}$ found between $88.40 \%-129.81 \%$ while the ISCV value for $\mathrm{LnC}_{\max }$ was $64.5 \%$.

Conclusion: The findings suggest that bioequivalence study for Alpha lipoic acid HR film tablet should be redesigned since this is a highly variable drug. Therefore, conventional bioequivalence acceptable limits $(80.0 \%-125.0 \%)$ should be adjusted to $69.84 \%-143.19 \%$ for alpha lipoic acid.
\end{abstract}

Keywords: Alpha lipoic acid, bioequivalence, highly variable drugs, intra-subject variability, replicate design

\section{INTRODUCTION}

Alpha lipoic acid (ALA), also known as thioctic acid, serves as a cofactor of mitochondrial respiratory enzymes, catalyzing oxidative decarboxylation reactions. ALA has been shown to possess antioxidant, cardiovascular, cognitive, anti-aging, detoxifying, anti-inflammatory, anti-cancer, and neuroprotective pharmacological properties. At present, it is mostly used for its antioxidant function (Ghelani, Razmovski-Naumovski, \& Nammi, 2017) and, in particular, it is widely used as a dietary supplement by the older adult population (Keith et al., 2012). ALA has two optical isomers, specifically R-ALA and S-ALA, and is commonly used in racemic mixture (R,S-ALA) (Mignini, Streccioni, Tomassoni, Traini, \& Amenta, 2007). It is readily absorbed following oral administration and is rapidly converted to dihydrolipoic acid (DHLA), its primary metabolite. ALA and its primary metabolite DHLA can directly regenerate ascorbic acid from dehydroascorbic acid and indirectly regenerate vitamin E. ALA also increases intracellular glutathione and coenzyme Q10 levels (Amenta, Traini, Tomassoni, \& Mignini, 2008).

In clinical trials alpha-lipoic acid has mainly been used in the treatment of symptomatic peripheral (sensorimotor) diabetic polyneuropathy. The reference product Thioctacid ${ }^{\oplus}$ (alpha lipoic acid) 600 mg HR (High Release) film coated tablet is manufactured by Meda 
Pharma, Germany. The pharmacokinetic parameters of the reference product evaluated in healthy volunteers under fasting condition are as follows: median time for peak absorption $\left(T_{\text {max }}\right)$ : $88.1 \mathrm{~min}$; area under the curve from time zero to the time of last measurable concentration (AUC $)$ : $3270.9 \mathrm{ng} \times \mathrm{h} / \mathrm{g}$; peak plasma concentration $\left(C_{\text {max }}\right): 1266.2 \mathrm{ng} / \mathrm{g}$ (Amenta et al., 2008).

The United States Food and Drug Administration (FDA) defines bioequivalence as 'the absence of a significant difference in the rate and extent to which the active ingredient or active moiety in pharmaceutical equivalents or pharmaceutical alternatives becomes available at the site of drug action when administered at the same molar dose under similar conditions in an appropriately designed study' (US FDA Code of Federal Regulations, 2019). For systemically available drug products, classical single-dose, two-period, two-sequence, and crossover RT/TR designs are used, wherein the reference product is denoted as $\mathrm{R}$ and the test product as $\mathrm{T}$. In this design, subjects receive a single test product dose and a reference product dose at randomly assigned times (Kang \& Vahl, 2017; Lohar et al., 2012). In some cases, the drugs studied can be highly variable according to their pharmacokinetic properties. As the subject is exposed to two doses of the same formulation at two different times in one study, the variability measured from the same subject is considered as intra-subject variability (Thota et al., 2013).

Highly variable drugs are commonly known to have an intrasubject (within-subject) coefficient of variability (ISCV) equal to or greater than 30\% in terms of AUC or $C_{\max }$ (Kang \& Vahl, 2017; Knahl, Lang, Fleischer, \& Kieser, 2018). Intra-subject variability can be estimated from study designs with more than two periods (Knahl et al., 2018). High intra-subject variability makes it difficult to obtain 90\% confidence interval (Cl 90\%) of the ratio between the test and reference products for log-transformed data in the acceptable bioequivalence interval (80.0\%-125.0\%) (Fagiolino, González, Vázquez, \& Eiraldi, 2007; Kang \& Vahl, 2017; Li et al., 2017). This may result in non-bioequivalence even with the same product due to the variability within it (Lohar et al., 2012). As a striking example, Siewert and coworkers (1990) could not demonstrate the bioequivalence of the product in a bioequivalence study conducted with 16 volunteers using the same product containing $80 \mathrm{mg}$ immediate-release verapamil (Blume et al., 1994). According to David et al.'s review study of the FDA's Office of Generic Drugs from 2003 to 2005, $31 \%$ of the bioequivalence studies conducted with 180 drugs were highly variable (Lohar et al., 2012; Molins, Cobo, \& Ocaña, 2017). At that time, the standard 2-way cross-over study designs could not be used for proving bioequivalence. Designs with more subjects and more periods, such as three- and four-period designs were needed to give an estimation of the relevant variability. Full-replicate designs such as TRTR/RTRT or partial-replicate designs such as TRR/RTR/RRT were developed (Knahl et al., 2018). The main requirement for developing replicate crossover designs in highly variable drugs was to enable subjects to receive at least one of the drug products more than once (Kang \& Vahl, 2017).

In the literature, some technical limitations are mentioned for oral formulations of alpha lipoic acid because of low solubility, short blood half-life, elevated systemic elimination, and firstpass hepatic metabolism (Mignini, Nasuti, Gioventu, Napolioni, \& Martino, 2012). The absolute bioavailability of alpha lipoic acid is around 30\% (Brufani \& Figliola, 2014). However, in addition to the lack of product-specific FDA and EMA guidelines including Alpha lipoic acid 600 mg HR tablet, there is no information available in the literature about the highly variable properties of this product. Therefore, researchers or generic drug development companies have to design a bioequivalence study for this product according to the general rules of the FDA and EMA bioequivalence guidance. If there is no special information about the highly variable properties, twoperiod, two-sequence, crossover RT/TR designs are generally used for classical single-dose products which is not suitable for this product. This study assesses bioequivalence of the test product (ILKO Pharmaceuticals) with the registered reference drug (Thioctacid ${ }^{\circledR} 600$ mg HR film coated tablet) in order to determine whether al pha lipoic acid in high release tablet dosage form is a highly variable drug product.

\section{MATERIALS AND METHODS}

API grade alpha lipoic acid active substance was obtained from Olon SPA Company (Milano-Italy) in racemic form. Lowsubstituted hydroxypropyl cellulose (Shin-Etsu Chemical Co. - Japan), hydroxypropyl cellulose (Nippon Soda Co. - Japan), magnesium stearate (FACI SPA - Spain), and hypromellose based coating materials (Colorcon, Inc. - England) were used as inactive ingredients in formulations. Analytical grades of potassium dihydrogen phosphate (Merck, Germany), phosphoric acid (ortho-phosphoric acid 85\%, Merck, Germany), methanol (J.T. Baker, Poland) and acetonitrile (J.T. Baker, Poland) were used in HPLC analysis. Quantitative stability indicating HPLC test methods were performed on Waters Alliance HPLC System equipped with the 2695 Separations Module (Waters, Milford, MA, USA) with variable wavelength UV-Detector and run with Empower-2 Software. Ultrapure deionized water was obtained from a Millipore water purification system (Millipore Corp., Bedford, MA, USA).

In all studies, the test product (T) alpha lipoic acid $600 \mathrm{mg} \mathrm{HR}$ film coated tablet manufactured by ILKO Pharmaceuticals, Turkey (Lot: 1305119001) and the reference product (R) Thioctacid $^{\circledR}$ (racemic alpha lipoic acid) 600 mg HR film coated tablet manufactured by Meda Pharma, Germany (Lot: 3741051) were used (Table 1).

\section{EXPERIMENTAL}

\section{Analytical methods}

Dissolved alpha lipoic acid content at in vitro condition was determined spectrophotometrically by a validated HPLC method at $215 \mathrm{~nm}$ using a Waters 2695 separation module (Waters, Milford, MA, USA). Separation was achieved on a C18 ACE 5 um column (4.6 mm $\times 250 \mathrm{~mm}$ ) using a mobile phase of buffer: methanol : acetonitrile (350:350:300). The buffer was prepared by dissolving $680 \mathrm{mg}$ of potassium dihydrogen phosphate in $1 \mathrm{~L}$ of deionized water and adjusted to $\mathrm{pH} 3.0$ with phosphoric acid. The flow rate was $1.2 \mathrm{~mL} / \mathrm{min}$, and the signal was monitored at a wavelength of $214 \mathrm{~nm}$. The analytical method 


\section{Table 1. Active substance and excipients of test product (T) Alpha lipoic acid $600 \mathrm{mg} \mathrm{HR}$ film tablet and reference product $(R)$ Thioctacid ${ }^{\oplus} \mathbf{6 0 0} \mathbf{m g ~ H R}$ film coated tablet.}

\begin{tabular}{|c|c|c|}
\hline & $\begin{array}{c}\text { Test Product }(\mathrm{T}) \\
\text { Alpha Lipoic Acid } 600 \mathrm{mg} \\
\text { HR Film Tablet }\end{array}$ & $\begin{array}{l}\text { Reference Product (R) } \\
\text { Thioctacid }^{\oplus} 600 \text { mg HR } \\
\text { Film Coated Tablet }\end{array}$ \\
\hline Active substance & - Alpha lipoic acid 600 mg & - Alpha lipoic acid 600 mg \\
\hline Excipients & $\begin{array}{c}\text { Core Tablet } \\
\text { - Poly (0-2-hydroxypropyl) cellulose } \\
\text { - Magnesium stearate } \\
\text { - Hydroxypropyl cellulose } \\
\text { - HPMC based film coating agents }\end{array}$ & $\begin{array}{c}\text { Core Tablet } \\
\text { - Poly (0-2-hydroxypropyl) cellulose } \\
\text { - Magnesium stearate } \\
\text { - Hydroxypropyl cellulose } \\
\text { - HPMC based film coating agents }\end{array}$ \\
\hline
\end{tabular}

of alpha lipoic acid was validated for specificity, selectivity, sensitivity, linearity, recovery, accuracy and precision parameters.

All the plasma samples from all subjects of in vivo bioequivalence study were assayed as per protocol criteria for alpha lipoic acid using a validated LC-MS/MS method. Nineteen (19) blood samples were collected from each subject during each period. The venous blood samples $(0.5 \mathrm{~mL}$ per sample) were withdrawn at pre-dose $[(0.00)$ (within 2.00 hours prior to dosing)] and at $0.083,0.167,0.25,0.33,0.50,0.67,0.83,1.00,1.25$, $1.50,1.75,2.00,2.50,3.00,4.00,5.00,6.00$ and 8.00 hours postdose. Samples from those subjects who completed at least two clinical study periods and who received test and reference products at least once were assayed. Plasma samples were assayed for alpha lipoic acid using Liquid Chromatography Tandem Mass Spectrometry (LC-MS/MS) method.

The method was developed and validated in-house with Guidance on Bioanalytical Method Validation by EMEA. This method for alpha lipoic acid was validated by solid phase extraction method for its selectivity, sensitivity, accuracy, precision and other parameters. Calibration curve standards were prepared by spiking known concentration of analyte into screened and pooled biological matrix.

\section{In vitro dissolution study}

Before the in vivo study, an in vitro dissolution study was conducted comparing the dissolution behavior of the test product $(T)$ and reference product $(R)$ to verify the similarity of the products. In vitro dissolution testing was performed using USP type II paddle apparatus at 75 rpm at 10, 15, 20, 30, 45 and 60 min using $900 \mathrm{~mL}$ of deionized water, $0.1 \mathrm{~N} \mathrm{HCl}, \mathrm{pH} 4.5$ acetate buffer and $\mathrm{pH} 6.8$ phosphate buffer dissolution media. The conditional release profiles of the test product and reference product were plotted as the cumulative percent of drug dissolved vs. time.

The dissolution profiles were compared; the dissolution profiles obtained were evaluated by similarity factor $\left(f_{2}\right)$ (Helmy \& Bedaiwy, 2013). According to the EMEA and FDA Guidelines, dissolution similarity may be determined using the $f_{2}$ statistic as follows:

$$
f 2=50 \cdot \log \left[\frac{100}{\sqrt{1+\frac{\sum_{t=1}^{n}[R(t)-T(t)]^{2}}{n}}}\right]
$$

In this equation (Eq.1) $f_{2}$ is the similarity factor, $\mathrm{n}$ is the number of time points, $R(t)$ is the mean percent reference drug dissolved at time $t$ after initiation of the study; $T(t)$ is the mean percent test drug dissolved at time $t$ after initiation of the study. For both the reference and test formulations, percent dissolution should be determined. An f2 value between 50 and 100 suggests that the two dissolution profiles are similar (EMEA Guideline on the Investigation of Bioequivalence, 2010).

\section{In vivo bioequivalence study}

Initially, a randomized, two-period, single-dose, two-way crossover oral bioequivalence study comparing the test product ( $T$ ) and reference product (R) was conducted in normal, healthy, adult human subjects under fasting conditions (indicated below as Study 1). According to the results, this study failed with a high ISCV value, and then it was decided to repeat the study with a full replicate study design proposed for highly variable products (indicated below as Study 2). The details of the two studies are presented below.

\section{Ethics statement}

The study protocol was approved by the Kavach Ethics Committee (ethics committee registration no: ECR/96/Indt/ AP/2013) from Drugs Control General of India (DCGI) on December 12, 2014 (approval number: T-BE-5341/14). The study was conducted in compliance with the approved protocols, ethical principles laid down in the Declaration of Helsinki, and Good Practice Guidelines issued under the applicable regulations. A written informed consent of volunteers was obtained following a detailed explanation of the procedures that they may undergo.

\section{Study subjects}

Adult, healthy, male volunteers between 22 to 45 years of age with a body mass index (BMI) between $18.5-30.0 \mathrm{~kg} / \mathrm{m}^{2}$ and a mean body weight of $45 \mathrm{~kg}$ were enrolled as the study subjects. Before the study, medical and surgical histories of the volunteers were determined by general clinical examinations and laboratory tests. The clinical phase of the study lasted 20 days.

The subjects maintained 10.00 hours of overnight fasting before the scheduled dosing time. According to the randomization schedule, each subject was administered either a single dose of the test product $(T)$ or reference product $(R)$ with $240 \pm 5 \mathrm{~mL}$ of water in a standing position at ambient temperature $\left(23 \pm 4^{\circ} \mathrm{C}\right)$. The subjects were instructed not to chew or crush the tablet but to consume it as a whole. They were 
instructed to maintain an upright posture (sitting) for the first two hours after dosing in each period except when a change of posture was clinically indicated or necessary.

\section{Study design}

Study 1: A randomized, open-label, balanced, two-treatment, two-period, two-sequence, single-dose, two-way crossover oral bioequivalence study comparing the test product $(T)$ and reference product $(R)$ in 24 normal, healthy, adult human subjects under fasting conditions.

Study 2: A randomized, open-label, balanced, two-treatment, four-period, two-sequence, single-dose, fully replicate crossover oral bioequivalence study comparing the test product ( $T$ ) and reference product (R) in 28 normal, healthy, adult human subjects under fasting conditions.

The randomization for the bioequivalence studies was generated using statistical software SAS ${ }^{\otimes}$ Version 9.4. Eighteen blood samples of $0.5 \mathrm{~mL}$ each were collected in vacutainers containing $\mathrm{K}_{2}$ EDTA from each subject during each period at pre-dose $[(0.00)$ within 2.00 hours prior to dosing $]$ and at $0.083,0.167$, $0.25,0.33,0.50,0.67,0.83,1.00,1.25,1.50,1.75,2.00,2.50,3.00$, $4.00,5.00$ and 6.00 hours post-dose. Plasma samples taken from the subjects who completed all clinical phases were analyzed. Quantification was performed with LC-MS/MS using solid-phase extraction method.

\section{Pharmacokinetic analysis}

Based on the plasma concentrations of alpha lipoic acid, pharmacokinetic parameters $\left(C_{\text {max }}, A \cup C_{0-t^{\prime}}, A^{\prime} C_{0-\infty}, T_{\text {max }}, K_{e}\right.$, and $\left.t_{1 / 2}\right)$ were calculated using "Non-compartmental model" for test and reference treatments. All pharmacokinetic analyses were carried out using WinNonlin Professional Software Version 5.4 (Pharsight Corporation, USA).

Pharmacokinetic parameters are summarized as follows: $C_{\max }$ $[\mathrm{ng} / \mathrm{mL}]$ is the observed maximum concentration in $\mathrm{ng} / \mathrm{ml}$, $\mathrm{AUC}_{0-\mathrm{t}}[\mathrm{ngxh} / \mathrm{mL}]$ is the area under the plasma concentration vs. time curve in $\mathrm{ngxh} / \mathrm{ml}, \mathrm{AUC}_{0-\infty}[\mathrm{ngxh} / \mathrm{mL}]$ is the area under the plasma concentration vs time curve, $T_{\max }[h]$ is the time observed to reach $C_{\max }$ and $t_{1 / 2}(\lambda)[h]$ is the terminal half-life calculated from $\lambda$ according to $t_{1 / 2}=\ln (2) / \lambda$.

\section{Statistical analysis}

Descriptive statistics (such as mean, minimum, maximum, standard deviation, standard error, median, CV\% geometric mean and coefficient of variation) were calculated for plasma concentrations of alpha lipoic acid at several time points as well as for the pharmacokinetic parameters $C_{\max }$ and $A U C_{0-t}$ of the test and reference treatments.

Statistical analyses were performed on the pharmacokinetic parameters using the SAS Statistical Software Version 9.4 or higher, SAS Institute. Inc., CARY, USA. ANOVA, and two onesided t-tests, 90\% confidence intervals, ratio analysis for $\mathrm{Ln}$ transformed $\mathrm{C}_{\max }$ and $\mathrm{AUC}_{0-\mathrm{t}}$ were calculated for the test and reference formulations.

If the intra-subject variability of the reference is $\leq 30 \%$ for $C_{\text {max }}$ then the $90 \%$ confidence intervals for the difference between treatments and least-squares means will be calculated for Lntransformed $C_{\max }$ and $\mathrm{AUC}_{0-\mathrm{t}}$.

If the intra-subject variability of the reference is $>30 \%$ for $C_{\max }$ (not resulting from outliers), then the $90 \% \mathrm{Cl}$ will be calculated according to the formula $[U, L]=\exp [ \pm k \cdot S W R]$, where $U$ is the upper limit of the acceptance range, $L$ is the lower limit of the acceptance range, $\mathrm{k}$ is the regulatory constant set to 0.760 and SWR is the within-subject standard deviation of the log-transformed values of $C_{\max }$ of the reference product.

The test and reference products showed similar relative bioavailability if the difference between compared parameters was found to be statistically insignificant ( $p>0.05$ ) and the $90 \%$ $\mathrm{Cl}$ for these parameters was found to be within $80 \%$ to $125 \%$. The acceptance range for $C_{\max }$ may be wider than that for $A \cup C$, particularly for drugs having highly variable peak concentrations; in such situations, the recommended range for $C_{\max }$ is 69.84\% to 143.19\% (Helmy \& Bedaiwy, 2013).

\section{Safety assessment}

The safety assessments included monitoring of adverse events comprising adverse drug reactions, periodic physical examination, vital signs at regular predetermined intervals and those determined by the principal investigator. Pre-study 12-lead ECG, chest X-ray, urine analysis, and serology were conducted for screening of volunteers. Pre-study hematology and serum chemistry assessments were done to select participants with baseline values within reference ranges or clinically non-significant values if outside the reference range. These were repeated in post-study stage to determine any clinically significant abnormality.

Urine drug screening and alcohol breath test were done during the enrollment period of the study to detect participants for any recent substance abuse. A clinical assessment, which includes general and systemic examination, was conducted initially during the pre-study screening and finally during the post-study examination. Blood glucose monitoring was done at 01.00 and 03.00 hours post-dose (within \pm 30 minutes of scheduled time) in each period or whenever the physician felt necessary during the conduct of the study.

\section{RESULTS AND DISCUSSION}

\section{Validation of analytical methods}

Analytical method for estimation of dissolved alpha lipoic acid in in vitro analysis was developed and validated using HPLC. Calibration curve for alpha lipoic acid ranged from $0.135 \mathrm{mg} /$ $\mathrm{mL}$ to $0.812 \mathrm{mg} / \mathrm{mL}$; correlation coefficient between concentrations and areas was higher than $0.99\left(r^{2}>0.99\right)$; recovery of analyte was $100.4 \%$.

Analytical method for estimation of alpha lipoic acid in human plasma was developed and validated using LC-MS/MS. The validated analytical method was used for analysis of plasma samples. Calibration curve for alpha lipoic acid ranged from 20.006 to $16004.569 \mathrm{ng} / \mathrm{mL}$; linear relationship between concentration and signal intensity were obtained $\left(r^{2}>0.99\right)$; the limit of quantitation (LOQ) was $20.006 \mathrm{ng} / \mathrm{mL}$; precision values were $2.5 \%, 3.9 \%, 3.2 \%$ and $4.0 \%$ at $9653.792 \mathrm{ng} / \mathrm{mL}, 6564.578$ 
$\mathrm{ng} / \mathrm{mL}, 1641.145 \mathrm{ng} / \mathrm{mL}$ and $50.875 \mathrm{ng} / \mathrm{mL}$ concentrations, respectively; accuracy values were 90.0\%, 92.6\%, 96.0\% and $95.0 \%$ at $9653.792 \mathrm{ng} / \mathrm{mL}, 6564.578 \mathrm{ng} / \mathrm{mL}, 1641.145 \mathrm{ng} / \mathrm{mL}$ and $50.875 \mathrm{ng} / \mathrm{mL}$ concentrations, respectively; recovery of analyte was $97.37 \%$.

\section{In vitro dissolution study results}

The results obtained confirmed that there were acceptable similarities between the test and reference products for various dissolution media (deionized water, $0.1 \mathrm{~N} \mathrm{HCl}, \mathrm{pH} 4.5 \mathrm{ac}-$ etate buffer and $\mathrm{pH} 6.8$ phosphate buffer) under comparison; as a result, $f 2$ values of all dissolution media are higher than 50. The results of in vitro tests confirm acceptable similarity between the test and reference products at different dissolution media such as deionized water, $0.1 \mathrm{~N} \mathrm{HCl}, \mathrm{pH} 4.5$ acetate buffer and $\mathrm{pH} 6.8$ phosphate buffer (Figure 1) having similarity factors $\left(f_{2}\right) 60.1,60.0,64.6$ and 70.7, respectively.

\section{Safety results}

As for these bioequivalence studies, the drugs were well tolerated upon single-dose administration to normal, healthy, adult, human subjects. No serious adverse events occurred during the conduct of these studies.

\section{Pharmacokinetic and statistical analysis results}

Pharmacokinetic parameters and statistical analyses of the test and reference products after administration to healthy vol- a)

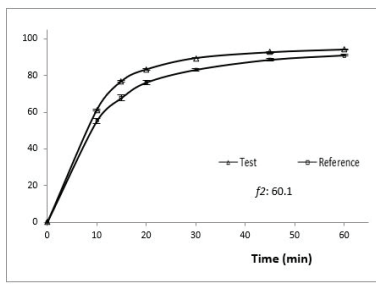

c)

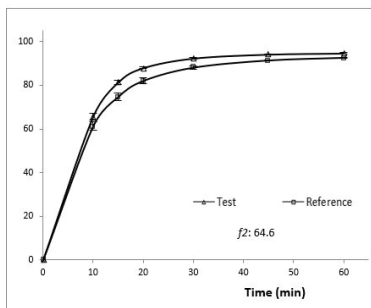

b)
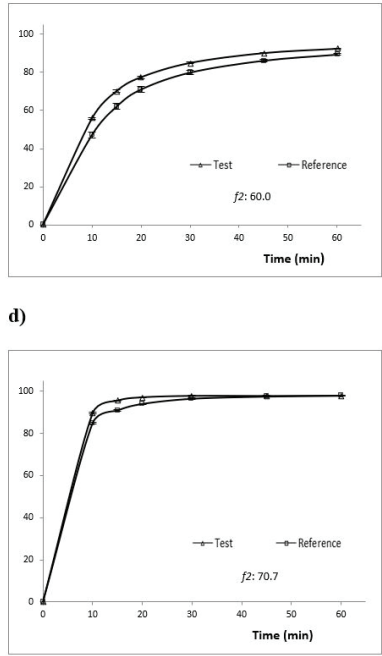

Figure 1. In vitro \% released alpha lipoic acid vs. time profiles from the test and reference products in four different conditions. a) deionized water; b) $0.1 \mathrm{~N} \mathrm{HCl}$; c) pH 4.5 acetate buffer; d) $\mathrm{pH} 6.8$ phosphate buffer. The data represent mean \pm standard error $(n=12)$.

unteers are summarized in Tables 2, 3 and 4, for both Study 1 and Study 2. For Study 1, the plan was for twenty-four healthy, adult, human subjects to take part, but only twenty-two completed the study. On the other hand, for Study 2, twenty-eight

Table 2. Pharmacokinetic parameters of alpha lipoic acid with the test (T) and reference (R) product for Study 1.

\begin{tabular}{|c|c|c|c|c|}
\hline \multicolumn{3}{|c|}{ Pharmacokinetic Parameters } & Test (T) & Reference (R) \\
\hline \multirow{25}{*}{ 章 } & $\mathrm{C}_{\max }(\mathrm{ng} / \mathrm{mL})$ & Mean & 5852.0 & 5049.6 \\
\hline & & Min - Max & $1085.7-19504.2$ & $1680.3-13827.8$ \\
\hline & & Median & 4514.2 & 3493.6 \\
\hline & & SD & 4722.7 & 3819.1 \\
\hline & & CV\% & 80.7 & 75.6 \\
\hline & $A U C_{0-t}$ & Mean & 3933.9 & 3815.6 \\
\hline & (ng $\cdot \mathrm{h} / \mathrm{mL}$ ) & Min - Max & $1604.1-7903.2$ & $1819.1-8139.7$ \\
\hline & & Median & 3769.8 & 3493.6 \\
\hline & & SD & 1685.0 & 1473.6 \\
\hline & & CV\% & 42.8 & 38.6 \\
\hline & $\mathrm{AUC}_{0-\infty}$ & Mean & 3998.3 & 3845.0 \\
\hline & $(\mathrm{ng} \cdot \mathrm{h} / \mathrm{mL})$ & Min - Max & $1691.5-7934.8$ & $1857.3-8156.2$ \\
\hline & & Median & 3795.6 & 3531.1 \\
\hline & & SD & 1689.5 & 1473.9 \\
\hline & & CV\% & 42.3 & 38.3 \\
\hline & $\mathrm{T}_{\max }(\mathrm{h})$ & Mean & 0.98 & 0.82 \\
\hline & & Median & 0.50 & 0.59 \\
\hline & & SD & 0.77 & 0.68 \\
\hline & & CV\% & 78.4 & 83.5 \\
\hline & $\mathrm{K}_{\mathrm{el}}(1 / \mathrm{h})$ & Mean & 1.3 & 1.7 \\
\hline & & SD & 0.59 & 0.54 \\
\hline & & $\mathrm{CV} \%$ & 44.5 & 32.5 \\
\hline & $t_{1 / 2}(h)$ & Mean & 0.66 & 0.47 \\
\hline & & SD & 0.36 & 0.17 \\
\hline & & CV\% & 54.2 & 36.8 \\
\hline
\end{tabular}


Table 3. Pharmacokinetic parameters of alpha lipoic acid with the test $(T)$ and reference $(R)$ product for Study 2 - replicate design.

\begin{tabular}{|c|c|c|c|c|}
\hline \multicolumn{3}{|c|}{ Pharmacokinetic Parameters } & Test (T) & Reference (R) \\
\hline \multirow{25}{*}{$\begin{array}{l}\text { No } \\
\text { के } \\
\dot{n}\end{array}$} & $\mathrm{C}_{\max }(\mathrm{ng} / \mathrm{mL})$ & Mean & 5215.8 & 4873.7 \\
\hline & & Min - Max & $592.4-19039.3$ & $803.1-11791.0$ \\
\hline & & Median & 4021.0 & 3655.0 \\
\hline & & SD & 3669.7 & 3131.6 \\
\hline & & CV\% & 70.4 & 64.3 \\
\hline & $A U C_{0-t}$ & Mean & 3648.7 & 3383.6 \\
\hline & $(\mathrm{ng} \cdot \mathrm{h} / \mathrm{mL})$ & Min - Max & $1263.4-9755.7$ & $803.1-11791.0$ \\
\hline & & Median & 3244.8 & 3232.0 \\
\hline & & SD & 1745.7 & 1406.9 \\
\hline & & CV\% & 47.8 & 41.6 \\
\hline & $\mathrm{AUC}_{0-\infty}$ & Mean & 3710.6 & 3413.5 \\
\hline & (ng.h/mL) & Min - Max & $1275.0-9786.7$ & $1301.2-7455.6$ \\
\hline & & Median & 3307.2 & 3285.8 \\
\hline & & SD & 1746.7 & 1398.7 \\
\hline & & CV\% & 47.1 & 41.0 \\
\hline & $\mathrm{T}_{\max }(\mathrm{h})$ & Mean & 0.96 & 0.98 \\
\hline & & Median & 0.59 & 0.67 \\
\hline & & SD & 0.80 & 0.69 \\
\hline & & CV\% & 83.7 & 70.2 \\
\hline & $\mathrm{K}_{\mathrm{el}}(1 / \mathrm{h})$ & Mean & 1.76 & 1.82 \\
\hline & & SD & 0.54 & 0.62 \\
\hline & & CV\% & 30.8 & 33.8 \\
\hline & $t_{1 / 2}(h)$ & Mean & 0.44 & 0.45 \\
\hline & & SD & 0.20 & 0.23 \\
\hline & & CV\% & 45.6 & 50.9 \\
\hline
\end{tabular}

Table 4. Statistical analysis for Log transformed $C_{\text {maxı }} A U C_{0-t,}, A U C_{0-\infty}$ data for test $(T)$ and reference (R) product.

\begin{tabular}{|c|c|c|c|c|c|c|c|c|}
\hline & & & & & tistical An & sis & & \\
\hline Pha & lacokinetic & Least Square & etric Mean & & & C.I. & & \\
\hline & & Reference & Test & & Lower & Upper & & \\
\hline & $\begin{array}{l}\mathrm{LnC}_{\max } \\
(\mathrm{ng} / \mathrm{mL})\end{array}$ & 4216.5 & 4006.6 & $105.2 \%$ & $79.7 \%$ & $139.0 \%$ & $57.5 \%$ & $37.1 \%$ \\
\hline 颃 & $\begin{array}{l}\operatorname{LnAUC}_{0-\mathrm{t}} \\
(\mathrm{ng} \cdot \mathrm{h} / \mathrm{mL})\end{array}$ & 3602.0 & 3580.8 & $100.6 \%$ & $89.7 \%$ & $112.8 \%$ & $22.3 \%$ & $94.2 \%$ \\
\hline & $\begin{array}{l}\operatorname{LnAUC}_{0-\infty} \\
(\mathrm{ng} \cdot \mathrm{h} / \mathrm{mL})\end{array}$ & 3668.3 & 3612.0 & $101.6 \%$ & $91.1 \%$ & $113.2 \%$ & $21.1 \%$ & $95.8 \%$ \\
\hline & $\begin{array}{l}\mathrm{LnC}_{\max } \\
(\mathrm{ng} / \mathrm{mL})\end{array}$ & 4056.1 & 3786.4 & $107.1 \%$ & $88.4 \%$ & $129.8 \%$ & $64.5 \%$ & $60.6 \%$ \\
\hline 祘 & $\begin{array}{l}\operatorname{LnAUC}_{0-\mathrm{t}} \\
(\mathrm{ng} \cdot \mathrm{h} / \mathrm{mL})\end{array}$ & 3266.2 & 364.2 & $106.6 \%$ & $99.5 \%$ & $114.7 \%$ & $22.2 \%$ & $100.0 \%$ \\
\hline & $\begin{array}{l}\operatorname{LnAUC}_{0-\infty} \\
(\mathrm{ng} \cdot \mathrm{h} / \mathrm{mL})\end{array}$ & 3312.3 & 3102.0 & $106.8 \%$ & $101.3 \%$ & $116.2 \%$ & $21.2 \%$ & $100.0 \%$ \\
\hline
\end{tabular}


healthy, adult, human subjects were enrolled and initially dosed at the beginning of the study. Twenty-two subjects completed four periods of the study, and twenty-eight subjects who completed at least two periods dosed with $T$ and $R$ were considered for pharmacokinetic and statistical analysis for alpha lipoic acid.

According to the results of Study 1, two-way crossover design study, the test product could not be considered to be bioequivalent to the reference product as the $90 \%$ confidence interval for $\mathrm{LnC}_{\max }(\mathrm{ng} / \mathrm{mL})$ was $79.69 \%$ - 138.98\% (ISCV=57.5\%). However, according to Study 2, a fully replicate design study, the test product was bioequivalent in terms of $\mathrm{LnAUC}_{0-\mathrm{t}}(\mathrm{ng} \cdot \mathrm{h} /$ $\mathrm{mL}$ ) and $\mathrm{LnAUC}_{0-\infty}(\mathrm{ng} \cdot \mathrm{h} / \mathrm{mL})$, but for $\mathrm{LnC}_{\max }(\mathrm{ng} / \mathrm{mL})$ the $90 \%$ confidence intervals (88.40\% - 129.81\%) were slightly higher than acceptable limits (80.0\%-125.0\%). When the intra-subject variations were considered, a moderately variable $\mathrm{LnAUC}_{0-\mathrm{t}}$ and LnAUC $_{0-\infty}$ having ISCV $22.2 \%$ and $21.2 \%$ respectively, and a highly variable $\mathrm{LnC}_{\max }$ (ISCV=64.5\%) which is much higher than 30\% were found. Therefore, intra-subject variabilities showed that alpha lipoic acid is a highly variable drug.

Mean plasma concentration vs. time profiles from 0 to 6 h obtained after administration of the test product and the reference product are shown in Figure 2. The curves after administration of the test or reference products are similar for alpha lipoic acid, especially for Study 2, a full replicate design study.
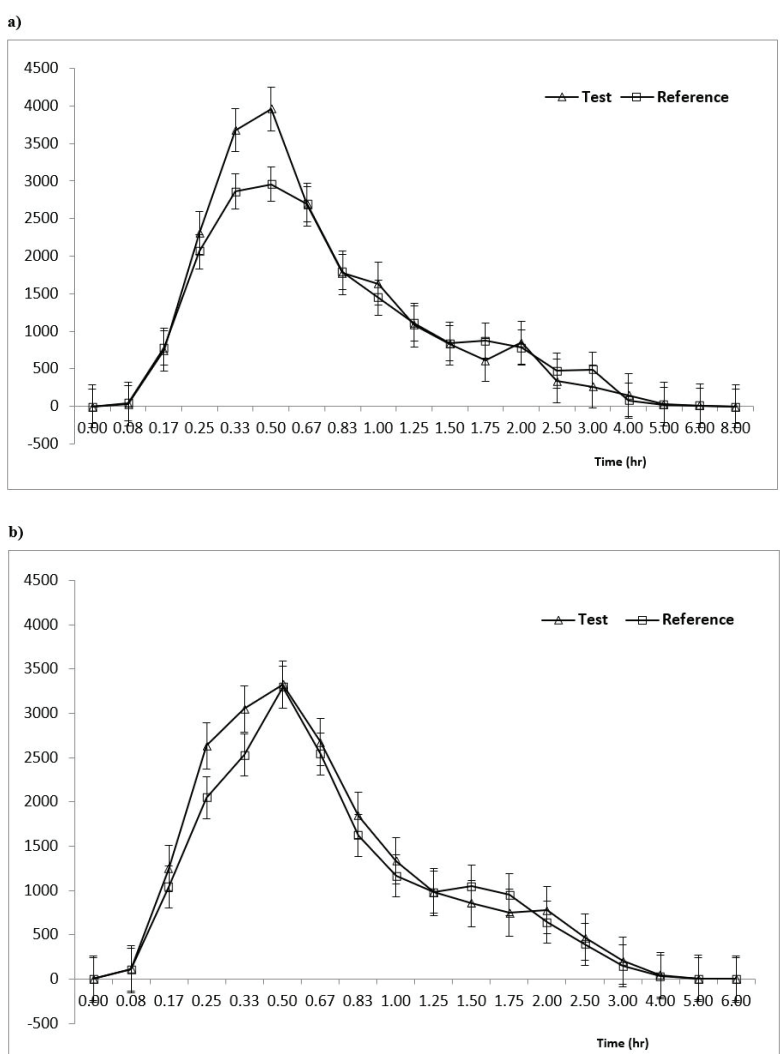

Figure 2. Mean \pm standard error (SE) plasma concentration vs. time profile of alpha lipoic acid following single oral dose administration of test $(T)$ and reference (R) product in healthy, adult, male volunteers under fasting condition. (a) Study 1 ( $n=22)$; (b) Study 2 Replicate design study $(n=28)$.

\section{CONCLUSION}

Alpha lipoic acid meets the criteria for a highly variable drug with respect to replicate design bioequivalence study results (Study 2). Alpha lipoic acid 600 mg HR film tablet, which does not have product-specific FDA and EMA bioequivalence guidance, has been shown to have high intra-subject variabilities. Therefore, conventional bioequivalence acceptable limits (80.0\%-125.0\%) should be adjusted to 69.84\%-143.19\% for alpha-lipoic acid. This study will contribute greatly to the literature and especially to pharmaceutical companies that develop generic products while designing the bioequivalence study.

Acknowledgement: The authors would like to thank to the colleagues at Illko Pharmaceutical R\&D Center for their contributions to this resarch.

Peer-review: Externally peer-reviewed.

Author Contributions: Conception/Design of Study- B.B., O.P.; Data Acquisition- B.B., O.P.; Data Analysis/Interpretation- B.B., O.P., N.S.; Drafting Manuscript- N.S.; Critical Revision of Manuscript- B.B., O.P., N.S.; Final Approval and Accountability- B.B., O.P., N.S.

Conflict of Interest: The authors have no conflict of interest to declare.

Financial Disclosure: This work was supported by Ilko Pharmaceuticals.

\section{REFERENCES}

- $\quad$ Amenta, F., Traini, E., Tomassoni, D., \& Mignini, F. (2008). Pharmacokinetics of different formulations of tioctic (alpha-lipoic) acid in healthy volunteers. Clinical and Experimental Hypertension, 30(8), 767-775. https://doi.org/10.1080/10641960802563568

- $\quad$ Blume, H., Zhong, D., Elze, M., Wendt, G., Schug, B., Scheidel, B. ... Hagenlocher, M. (1994). Advantages of a steady-state crossover design in assessment of bioequivalence of highly variable drugs: propafenone. European Journal of Pharmaceutical Sciences, 2(5-6), 385-393. https://doi.org/10.1016/0928-0987(94)00068-9

- $\quad$ Brufani, M., \& Figliola, R. (2014). (R)-a-lipoic acid oral liquid formulation: pharmacokinetic parameters and therapeutic efficacy. Acta Bio-Medica: Atenei Parmensis, 85(2), 108-115. Retrieved from https://www.mattioli1885journals.com/index.php/actabiomedica/article/view/3800

- $\quad$ Fagiolino, P., González, N., Vázquez, M., \& Eiraldi, R. (2007). Itraconazole Bioequivalence Revisited: Influence of Gender on Highly Variable Drugs. The Open Drug Metabolism Journal, 1, 7-13. http:// dx.doi.org/10.2174/1874073100701010007

- Ghelani, H., Razmovski-Naumovski, V., \& Nammi, S. (2017). Chronic treatment of (R)-a-lipoic acid reduces blood glucose and lipid levels in high-fat diet and low-dose streptozotocin-induced metabolic syndrome and type 2 diabetes in Sprague-Dawley rats. Pharmacology Research \& Perspectives, 5(3). https://doi. org/10.1002/prp2.306

- Helmy, S. A., \& El Bedaiwy, H. M. (2013). Comparative in vitro dissolution and in vivo bioavailability of diflunisal/naproxen fixeddose combination tablets and concomitant administration of diflunisal and naproxen in healthy adult subjects. Drug Research, 63(3), 150-158. http://dx.doi.org/10.1055/s-0033-1333768

- Kang, Q., \& Vahl, C. I. (2017). Testing for bioequivalence of highly variable drugs from TR-RT crossover designs with heterogeneous residual variances. Pharmaceutical Statistics, 16(5), 361-377. http://doi.org/10.1002/pst.1816 
- Keith, D. J., Butler, J. A., Bemer, B., Dixon, B., Johnson, S., Garrard, M. ... Hagen, T. M. (2012). Age and gender dependent bioavailability of R- and R,S-a-lipoic acid: A pilot study. Pharmacological Research, 66(3), 199-206. http://doi.org/10.1016/j.phrs.2012.05.002

- Knahl, S. I., Lang, B., Fleischer, F., \& Kieser, M. (2018). A comparison of group sequential and fixed sample size designs for bioequivalence trials with highly variable drugs. European Journal of Clinical Pharmacology, 74(5), 549-559. https://doi.org/10.1007/s00228018-2415-7

- $\quad$ Li, C., Xu, J., Zheng, Y., Chen, G., Wang, J., Ma, L. ... Ding, Y. (2017). Bioequivalence and Pharmacokinetic Profiles of Agomelatine 25-mg Tablets in Healthy Chinese Subjects: A Four-Way Replicate Crossover Study Demonstrating High Intra- and Inter-Individual Variations. Chemical \& Pharmaceutical Bulletin, 65(6), 524529. https://doi.org/10.1248/cpb.c16-00866

- Lohar, V., Patel, H., Rathore, A. S., Singhal, S., Sharma, A. K., \& Sharma, P. (2012). Bioequivalence and highly variable drugs: an overview. International Journal of Current Research and Review, 04(08), 124146. Retrieved from https://www.ijcrr.com/uploads/1853_pdf.pdf

- Mignini, F., Streccioni, V., Tomassoni, D., Traini, E., \& Amenta, F. (2007). Comparative Crossover, Randomized, Open-Label Bioequivalence Study on the Bioequivalence of Two Formulations of Thioctic Acid in Healthy Volunteers. Clinical and Experimental Hypertension, 29(8), 575-586. http://dx.doi. org/10.1080/10641960701744111
Mignini, F., Nasuti, C., Gioventu, G., Napolioni, V., \& Martino, P. D. (2012). Human Bioavailability and Pharmacokinetic Profile of Different Formulations Delivering Alpha Lipoic Acid. Open Access Scientific Reports, 1(8), 418. http://dx.doi.org/10.4172/scientificreports.418

- Molins, E., Cobo, E., \& Ocaña, J. (2017). Two-stage designs versus European scaled average designs in bioequivalence studies for highly variable drugs: Which to choose? Statistics in Medicine, 36(30), 4777- 4788. https://doi.org/10.1002/sim.7452

- $\quad$ Thota, S., Khan, S. M., Tippabhotla, S. K., Battula, R., Gadiko, C., \&Vobalaboina, V. (2013). Bioequivalence of two lansoprazole delayed release capsules $30 \mathrm{mg}$ in healthy male volunteers under fasting, fed and fasting-applesauce conditions: A partial replicate crossover study design to estimate the pharmacokinetics of highly variable drugs. Drug Research, 63(11), 551-557. http://dx.doi. org/10.1055/s-0033-1347236

US FDA Code of Federal Regulations. (2019, April). Title 21, Section 314.3 Definitions. Retrieved from https://www.accessdata. fda.gov/scripts/cdrh/cfdocs/cfcfr/CFRSearch.cfm?fr=314.3 